\title{
A gluten-free diet effectively reduces symptoms and health care consumption in a Swedish celiac disease population
}

\author{
Fredrik Norström ${ }^{1 *}$, Olof Sandström,2, Lars Lindholm and Anneli Ivarsson ${ }^{1}$
}

\begin{abstract}
Background: A gluten-free diet is the only available treatment for celiac disease. Our aim was to investigate the effect of a gluten-free diet on celiac disease related symptoms, health care consumption, and the risk of developing associated immune-mediated diseases.

Methods: A questionnaire was sent to 1,560 randomly selected members of the Swedish Society for Coeliacs, divided into equal-sized age- and sex strata; 1,031 (66\%) responded. Self-reported symptoms, health care consumption (measured by health care visits and hospitalization days), and missed working days were reported both for the year prior to diagnosis (normal diet) and the year prior to receiving the questionnaire while undergoing treatment with a gluten-free diet. Associated immune-mediated diseases (diabetes mellitus type 1, rheumatic disease, thyroid disease, vitiligo, alopecia areata and inflammatory bowel disease) were self-reported including the year of diagnosis.
\end{abstract}

Results: All investigated symptoms except joint pain improved after diagnosis and initiated gluten-free diet. Both health care consumption and missed working days decreased. Associated immune-mediated diseases were diagnosed equally often before and after celiac disease diagnosis.

Conclusions: Initiated treatment with a gluten-free diet improves the situation for celiac disease patients in terms of reduced symptoms and health care consumption. An earlier celiac disease diagnosis is therefore of great importance.

\section{Background}

In celiac disease $(C D)$, gluten triggers an autoimmune reaction in the small intestinal mucosa which results in inflammation, villous atrophy, and malabsorption. A gluten-free diet is the only effective treatment for $\mathrm{CD}$, and it usually results in recovery of the small intestinal mucosa [1].

During the last 30 years the clinical spectrum of CD has changed from mainly being comprised of young children with overt malabsorption to often affecting adults, with mild or atypical symptoms, and some of those diagnosed with the disease are even asymptomatic [2]. Despite an increased awareness of symptoms related to $\mathrm{CD}$, the delay from the first appearance of $\mathrm{CD}$ related symptoms to

\footnotetext{
* Correspondence: fredrik.norstrom@epiph.umu.se

'Department of Public Health and Clinical Medicine, Epidemiology and

Global Health, Umeå University, Umeå, Sweden

Full list of author information is available at the end of the article
}

diagnosis is still long [3-5]. Economic consequences of CD for individuals and society have undergone little study. It has been shown, however, that the cost of food for CD patients is higher than for non-CD persons [6], and that women with $\mathrm{CD}$ consume more health care than other women [7]. CD diagnosis and treatment has also been shown to decrease the costs for medical care in the United States, suggesting that a diagnosis can convey economic savings for society $[8,9]$. There is an association between $\mathrm{CD}$ and other immune-mediated diseases, with $\mathrm{CD}$ being more prevalent among diabetes mellitus type 1 and thyroid disease patients [10-12] and inflammatory bowel disease and thyroid disease being more prevalent among $\mathrm{CD}$ patients [13-15]. A protective effect of a gluten-free diet on the risk of developing these related diseases has been proposed [16,17], but there is uncertainty in this regard [15,18-20].

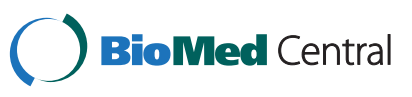


The aim of this study was to investigate the effect of a gluten-free diet on $\mathrm{CD}$ related symptoms, health care consumption, and the risk of developing associated immune-mediated diseases.

\section{Methods}

Study design

A cross-sectional questionnaire survey among Swedish adults with CD was performed during 2009 [5]. The questionnaire was approved by the Regional Ethical Review Board at Umeå University and an English translation is available online at Biomed Central [21].

\section{Subjects}

We invited randomly selected members of the Swedish Society for Coeliacs to respond to a postal questionnaire administered by the Society, and when needed three reminders were sent. The Society represents about $60 \%$ of Swedish CD patients [5]. A questionnaire was sent to 65 males and 65 females with reported $C D$ in five-year age intervals from 20 years of age and above (20-24, $25-29, \ldots, 70-74$, and 75 years or older), totaling 1,560 members. There were 1,031 (66\%) eligible responses to the questionnaire. Members self-report their CD diagnosis when joining the Society. As the diagnosis is not verified by the Society, we used information from the questionnaire about how members were diagnosed (blood sample, biopsy, and/or diet change) and if they were recommended adherence to a gluten-free diet by a medical professional. We excluded 91 questionnaires where either a CD diagnosis could not be verified or age and/or sex were not consistent with information in the member register of the society [5]. We defined 288 responders as diagnosed due to screening of $\mathrm{CD}$ risk groups. For them the primary investigation for $\mathrm{CD}$ was based on a disease with a known relationship to $\mathrm{CD}$ or due to heredity for CD. Among responders, 96\% reported a strict compliance with a gluten-free diet, $52 \%$ $(\mathrm{n}=536)$ were women, and the mean age was 52 years (Table 1). More characteristics of the study population, as well as more details about inclusion criteria, are available in a previous publication from the questionnaire study [5]. Questionnaires were scanned and checked for consistency.

\section{The questionnaire}

The questionnaire included sections covering selfreported symptoms, health care consumption, missed working days, and self-reported diseases. For each symptom (listed in Figure 1) there were five possible answers, which were dichotomized to major ("often" and "always") and minor severity ("never", "rarely", and "sometimes"). Health care consumption included number of health care visits, hospitalization days, and drug use. Missed working days also included missed school days and similar circumstances. For both symptoms, health care consumption, and missed working days the respondents were asked about the situation both the year prior to initiated treatment for $\mathrm{CD}$, referred to as pre-treatment, as well as the year prior to responding to the questionnaire, referred to as today. Regarding drug use, respondents were asked if their CD diagnosis and gluten-free diet had resulted in them being able to stop taking any medication.

Respondents reported whether they had the following immune-mediated diseases: diabetes (both insulin and non-insulin dependent; the latter is not autoimmune in nature), rheumatic disease, thyroid disease, vitiligo, alopecia areata, or inflammatory bowel disease. Regarding these diseases the respondents were also asked for the year of diagnosis. As respondents were asked about insulin or non-insulin dependent diabetes, we cannot with certainty differentiate between diabetes mellitus type 1 and 2 .

\section{Statistical analysis}

Results are presented using descriptive statistics. The signtest was used for comparisons between pre-treatment and today. Time between diagnoses was calculated as time from $\mathrm{CD}$ diagnosis to other disease diagnosis. When both diagnoses occurred during the same year, time was defined

Table 1 Characteristics of celiac disease subjects

\begin{tabular}{|c|c|c|c|c|c|c|}
\hline & \multirow[t]{2}{*}{$\mathbf{n}$} & \multirow[t]{2}{*}{$\%$} & \multirow[t]{2}{*}{ Mean } & \multirow[t]{2}{*}{ Median } & \multicolumn{2}{|c|}{ Quartile } \\
\hline & & & & & $1 s t$ & $3 r d$ \\
\hline Participants & 1,031 & & & & & \\
\hline Males/Females & $495 / 536$ & $48 / 52$ & & & & \\
\hline Age when responding (years) & 1,031 & & 52 & 53 & 36 & 67 \\
\hline Age at diagnosis (years) & 945 & & 39 & 41 & 27 & 53 \\
\hline Duration of celiac disease diagnosis (years) & 945 & & 10 & 13 & 5 & 19 \\
\hline Compliance with a gluten-free diet & 1,025 & & & & & \\
\hline Strict/Non-strict & 979/46 & $96 / 4$ & & & & \\
\hline
\end{tabular}

${ }^{a}$ Members were invited based on entrance to society latest $1^{\text {st }}$ of April 2009. Duration of celiac disease diagnosis was calculated as years ahead of 2009 that respondent was diagnosed. 


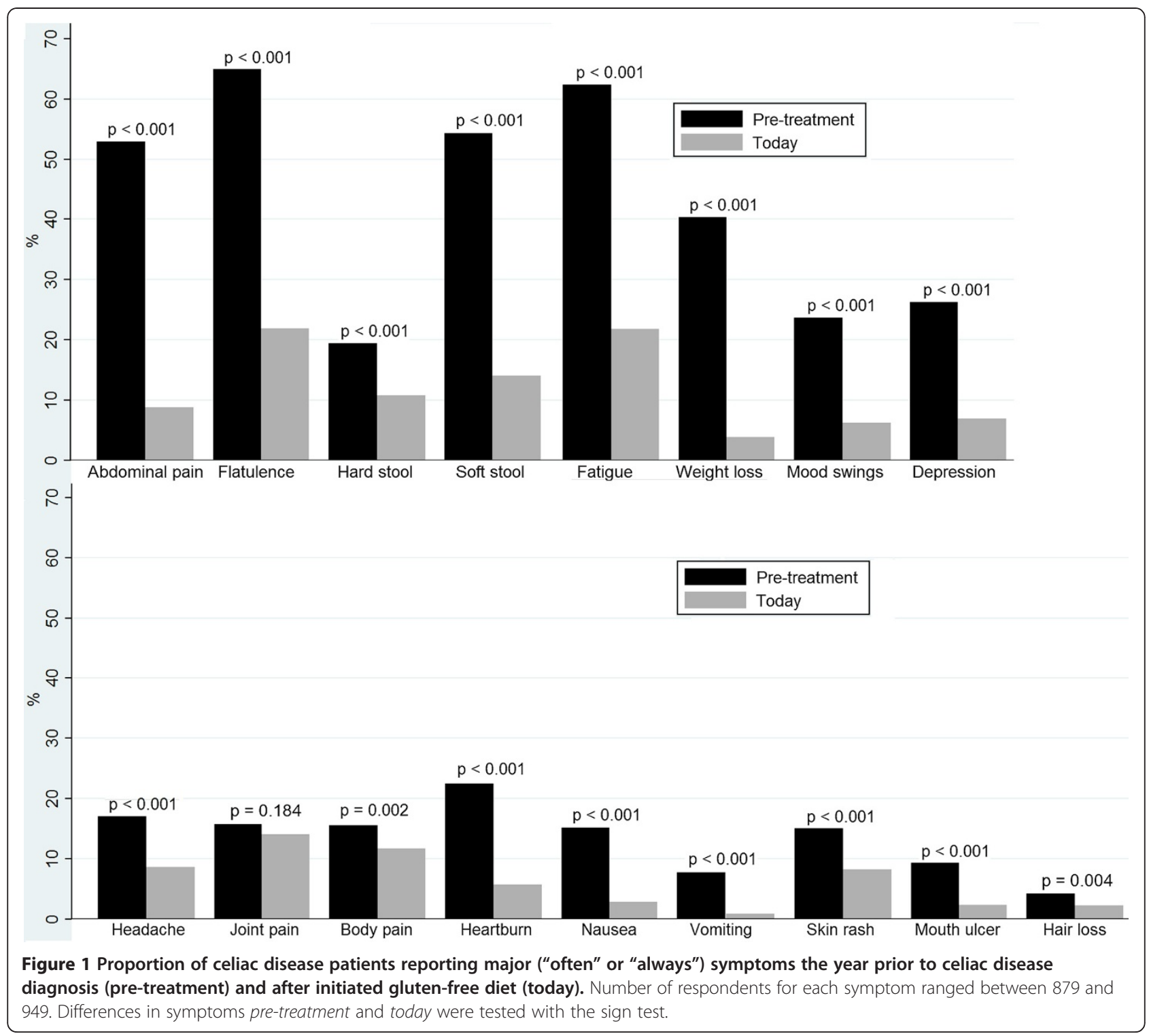

as 0 years. Differences in symptoms between members with a recent diagnosis (2005-2009) and members with earlier diagnosis were performed using Students $t$-test. Comparisons of health care visits, hospitalization days, and missed working days between the groups were performed using Wilcoxon rank-sum test. To test if a glutenfree diet might decrease the risk for associated diseases, the proportions of diagnoses of associated diseases before or during the same year as the CD diagnosis were compared with the proportions after CD diagnosis using Students $t$-test. We excluded comparisons for vitiligo and alopecia areata due to too few complete answers. Statistical significance was defined at the $5 \%$ level. Microsoft Access was used for data handling, while Stata 11.2 (StataCorp LP, College Station, TX) was used for statistical analysis and figures.

\section{Results}

\section{Symptoms}

Pre-treatment, flatulence (64\%) was the most commonly reported symptom, followed by fatigue $(62 \%)$, soft stool (54\%), and abdominal pain (53\%). All investigated symptoms, except joint pain, improved after diagnosis and initiated treatment with a gluten-free diet (Figure 1). Today, flatulence and fatigue were also the most commonly reported symptoms for all participants, even those who did not report the symptom pre-treatment (Table 2). It was less common that participants without a specific symptom reported pre-treatment reported the symptom today than it was for participants who reported the symptom pre-treatment. There were improvements in all investigated symptoms in the screening-detected cases except joint pain and body 
Table 2 Patients with symptoms today, also presenting for patients asymptomatic pre-treatment

\begin{tabular}{lrrrrrr}
\hline Symptom & \multicolumn{2}{c}{ All } & & \multicolumn{3}{c}{ Asymptomatic } \\
\cline { 6 - 7 } & $\mathbf{n}^{\mathbf{b}}$ & $\mathbf{\%}^{\mathbf{b}}$ & & $\mathbf{n}^{\mathbf{a}}$ & $\mathbf{n}^{\mathbf{b}}$ & $\%^{\mathbf{b}}$ \\
\hline Abdominal pain $(n=918)$ & 81 & 8.8 & 432 & 14 & $3.2^{*}$ \\
Flatulence $(n=897)$ & 189 & 21 & 324 & 46 & $14^{*}$ \\
Hard stool $(n=879)$ & 95 & 11 & 708 & 43 & $6.1^{*}$ \\
Soft stool $(n=926)$ & 130 & 14 & 423 & 24 & $5.7^{*}$ \\
Fatigue $(n=927)$ & 202 & 22 & 349 & 42 & $12^{*}$ \\
Weight loss $(n=903)$ & 35 & 3.8 & 539 & 11 & $2.0^{*}$ \\
Mood swings $(n=903)$ & 56 & 6.2 & 689 & 13 & $1.9^{*}$ \\
Depression $(n=913)$ & 63 & 6.9 & 673 & 13 & $1.9^{*}$ \\
Headache $(n=894)$ & 77 & 8.6 & 742 & 21 & $2.8^{*}$ \\
Joint pain $(n=897)$ & 126 & 14 & 756 & 48 & $6.3^{*}$ \\
Body pain $(n=897)$ & 105 & 12 & 758 & 43 & $5.7^{*}$ \\
Heartburn $(n=891)$ & 51 & 5.7 & 691 & 16 & $2.3^{*}$ \\
Nausea $(n=898)$ & 26 & 2.9 & 762 & 12 & $1.6^{*}$ \\
Vomiting $(n=910)$ & 8 & 0.8 & 840 & 6 & 0.7 \\
Skin rash $(n=898)$ & 74 & 8.2 & 763 & 26 & $3.4^{*}$ \\
Mouth ulcer $(n=904)$ & 21 & 2.3 & 820 & 10 & $1.2^{*}$ \\
Hair loss $(n=880)$ & 20 & 2.3 & 843 & 9 & $1.1^{*}$ \\
\hline
\end{tabular}

${ }^{a}$ Not reporting specific symptom pre-treatment.

${ }^{b}$ Reporting symptom today.

* Asymptomatic patients report fewer problems with symptom than symptomatic patients today.

pain. Due to too few cases, comparison between pretreatment and today was not feasible for vomiting and hair loss in the screening-detected group. For recently diagnosed cases (2005-2009), all investigated symptoms except vomiting and hair loss, which were rare in our study population, improved after diagnosis. The only differences between recently diagnosed and those with an earlier CD diagnosis was that weight loss and vomiting were less common in the former pre-treatment, joint pain was more common for recently diagnosed cases pre-treatment, and nausea was less common for recently diagnosed cases today.

\section{Health care consumption}

Participants reported more frequent health care visits pre-treatment (5.4 visits during the year) than today (3.7 visits during the year) $(\mathrm{p}<0.001)$, more hospitalization days (2.3 days during the year) pre-treatment compared to today (0.7 days during the year) $(\mathrm{p}<0.001)$, and more missed working days pre-treatment (7.2 days during the year) than today ( 2.5 days during the year) $(\mathrm{p}<0.001$ ) (Table 3). For screening-detected CD patients there were also reductions in health care visits, hospitalization days and missed working days between pre-treatment and today. For recently diagnosed patients (2005-2009) there were reductions in health care visits and missed working days, but not in hospitalization days. We observed significantly fewer hospitalization days pre-treatment and significantly fewer health care visits today for recently diagnosed patients as compared to patients earlier diagnosed. Thirteen percent of participants $(n=136)$ reported that they stopped taking at least one drug after their $\mathrm{CD}$ diagnosis.

\section{Self-reported immune-mediated diseases}

At least one immune-mediated disease was reported by $256(25 \%)$ of the study participants. Autoimmune thyroid disease, reported by $9.1 \%$, was the most prevalent

Table 3 Health care consumption pre-treatment and today

\begin{tabular}{|c|c|c|c|c|c|c|c|c|c|}
\hline \multirow[t]{2}{*}{ Disease } & & \multirow[b]{2}{*}{$\mathbf{n}$} & \multicolumn{3}{|c|}{ Pre-treatment } & \multicolumn{3}{|c|}{ Today } & \multirow[t]{2}{*}{$p^{a}$} \\
\hline & & & Mean & Median & SD & Mean & Median & SD & \\
\hline \multicolumn{10}{|l|}{ All } \\
\hline & Health care visits & 814 & 5.4 & 3 & 7.8 & 3.7 & 2 & 8.0 & $<0.001$ \\
\hline & Hospitalization & 836 & 2.3 & 0 & 8.5 & 0.7 & 0 & 4.0 & $<0.001$ \\
\hline & Missed working days ${ }^{b}$ & 754 & 7.2 & 0 & 16 & 2.5 & 0 & 9.6 & $<0.001$ \\
\hline \multicolumn{10}{|c|}{ Screening-detected cases $^{c}$} \\
\hline & Health care visits & 144 & 4.8 & 2 & 9.0 & 4.1 & 1 & 9.9 & 0.001 \\
\hline & Hospitalization & 151 & 3.0 & 0 & 11 & 1.0 & 0 & 5.4 & 0.036 \\
\hline & Missed working days ${ }^{b}$ & 136 & 9.0 & 0 & 21 & 1.8 & 0 & 7.4 & $<0.001$ \\
\hline \multicolumn{10}{|c|}{ Recent diagnosis $^{d}$} \\
\hline & Health care visits & 202 & 5.0 & 3 & 7.1 & 4.3 & 2 & 8.8 & $<0.001$ \\
\hline & Hospitalization & 200 & 0.62 & 0 & 2.7 & 0.36 & 0 & 1.8 & 0.860 \\
\hline & Missed working days ${ }^{b}$ & 188 & 7.5 & 0 & 17 & 3.4 & 0 & 13 & $<0.001$ \\
\hline
\end{tabular}

\footnotetext{
a Using the sign test.

b Also including missed school days and similar circumstances.

c Primary investigation started based on a disease with known relation to CD or due to heredity for CD.

${ }^{d}$ CD diagnosis between 2005 and 2009.
} 
immune-mediated disease (Table 4). There was a predominance of females for rheumatic disease and autoimmune thyroid disease but not for other self-reported associated diseases. There was no difference in the frequency of being diagnosed prior to or after $\mathrm{CD}$ diagnosis for any of the associated diseases (Figure 2).

\section{Discussion}

CD patients suffer from more symptoms and consume more health care before diagnosis and initiated glutenfree diet than they do afterwards. However, we did not observe a difference in the risk of developing other immune-mediated diseases after initiated treatment with a gluten-free diet.

This study is one of the largest of its kind and it has a high response rate. Its unique contribution is that it compares the situation before and after initiation of a gluten-free diet, including symptoms and health care consumption, which adds valuable information about individual and societal costs of untreated CD.

Our retrospective approach involves the risk of recall bias. We observed a similar pattern for symptom relief, health care visits, and missed working days when restricting our analysis to screened and recently diagnosed (2005-2009) CD patients. There was not a significant reduction in hospitalization days for the recently diagnosed (2005-2009) CD patients. This could indicate an improved situation due to earlier diagnosis, which we have reported earlier in the same population [5], or it might be due to problems remembering hospitalization days if diagnosed earlier than 2005. In an attempt to assess if the risk of developing associated immune-mediated diseases is affected by a gluten-free diet, we assumed that if fewer were diagnosed with the related disease after the $C D$ diagnosis this would indicate a protective effect. The patient is likely to remember which disease was diagnosed first, but if there is a delay in diagnosis for one of the diseases the association could still be incorrect. A causal relation cannot be determined with certainty by a cross-sectional questionnaire study. An examination of hospital files would have been a valuable addition in this respect, but that was not within the scope of this study.

Retrospectively reported symptoms prior to a CD diagnosis have been studied previously [4], as have symptoms at the time of CD diagnosis [22-25]. Most studies have reported symptoms at the time of diagnosis that were obtained from medical records, making comparisons with our results difficult. Our main interest was to detect experienced changes in symptoms after initiated treatment with a gluten-free diet.

Table 4 Proportion of immune-mediated diseases and time development in relation to celiac disease (CD) diagnosis

\begin{tabular}{|c|c|c|c|c|c|c|c|c|c|c|}
\hline & & All & Males & Females & $p^{a}$ & Before & Jointly $^{b}$ & After & $n^{c}$ & $p^{d}$ \\
\hline \multirow[t]{2}{*}{ Diabetes, insulin } & $n$ & 39 & 24 & 15 & 0.19 & $53 \%$ & $6 \%$ & $41 \%$ & 32 & 0.29 \\
\hline & $\%$ & 3.8 & 4.8 & 2.8 & & & & & & \\
\hline \multirow[t]{2}{*}{ Diabetes, non-insulin } & $n$ & 24 & 17 & 7 & 0.04 & $20 \%$ & $13 \%$ & $67 \%$ & 15 & 0.20 \\
\hline & $\%$ & 2.3 & 3.4 & 1.3 & & & & & & \\
\hline \multirow[t]{2}{*}{ Rheumatic disease } & $n$ & 80 & 19 & 61 & $<0.01$ & $42 \%$ & $8 \%$ & $50 \%$ & 48 & 1.00 \\
\hline & $\%$ & 7.8 & 3.8 & 11 & & & & & & \\
\hline \multirow[t]{2}{*}{ Thyroid disease } & $n$ & 94 & 19 & 75 & $<0.01$ & $47 \%$ & $15 \%$ & $38 \%$ & 68 & $0.05^{\mathrm{e}}$ \\
\hline & $\%$ & 9.1 & 3.8 & 14 & & & & & & \\
\hline \multirow[t]{2}{*}{ Vitiligo } & $n$ & 39 & 16 & 23 & 0.24 & $72 \%$ & $11 \%$ & $17 \%$ & 18 & $<0.01$ \\
\hline & $\%$ & 3.8 & 3.2 & 4.3 & & & & & & \\
\hline \multirow[t]{2}{*}{ Alopecia areata } & $n$ & 19 & 11 & 8 & 0.52 & $62 \%$ & $8 \%$ & $31 \%$ & 13 & 0.16 \\
\hline & $\%$ & 1.8 & 2.2 & 1.5 & & & & & & \\
\hline \multirow[t]{2}{*}{ Inflammatory bowel disease } & $n$ & 44 & 17 & 27 & 0.09 & $31 \%$ & $27 \%$ & $42 \%$ & 26 & 0.43 \\
\hline & $\%$ & 4.3 & 3.4 & 5.0 & & & & & & \\
\hline \multirow[t]{2}{*}{ Any immune-mediated disease $e^{e}$} & $n$ & 256 & 170 & 86 & $<0.01$ & $n / a^{f}$ & $\mathrm{n} / \mathrm{a}$ & $n / a$ & $\mathrm{n} / \mathrm{a}$ & $n / a$ \\
\hline & $\%$ & 25 & 32 & 17 & & & & & & \\
\hline
\end{tabular}

${ }^{\text {a }}$ Comparing males with females using Students $t$-test.

${ }^{\mathrm{b}} \mathrm{CD}$ associated immune-mediated disease reported for same year as $\mathrm{CD}$ diagnosis.

c Specified year for both CD and other diagnosis.

${ }^{d}$ Comparing proportion with auto-immune disease diagnosed before or jointly with $C D$ with proportion after CD diagnosis.

e Non-significant.

${ }^{f}$ Not including non-insulin dependent diabetes.

${ }^{g}$ Comparisons not applicable for "Any disease". 


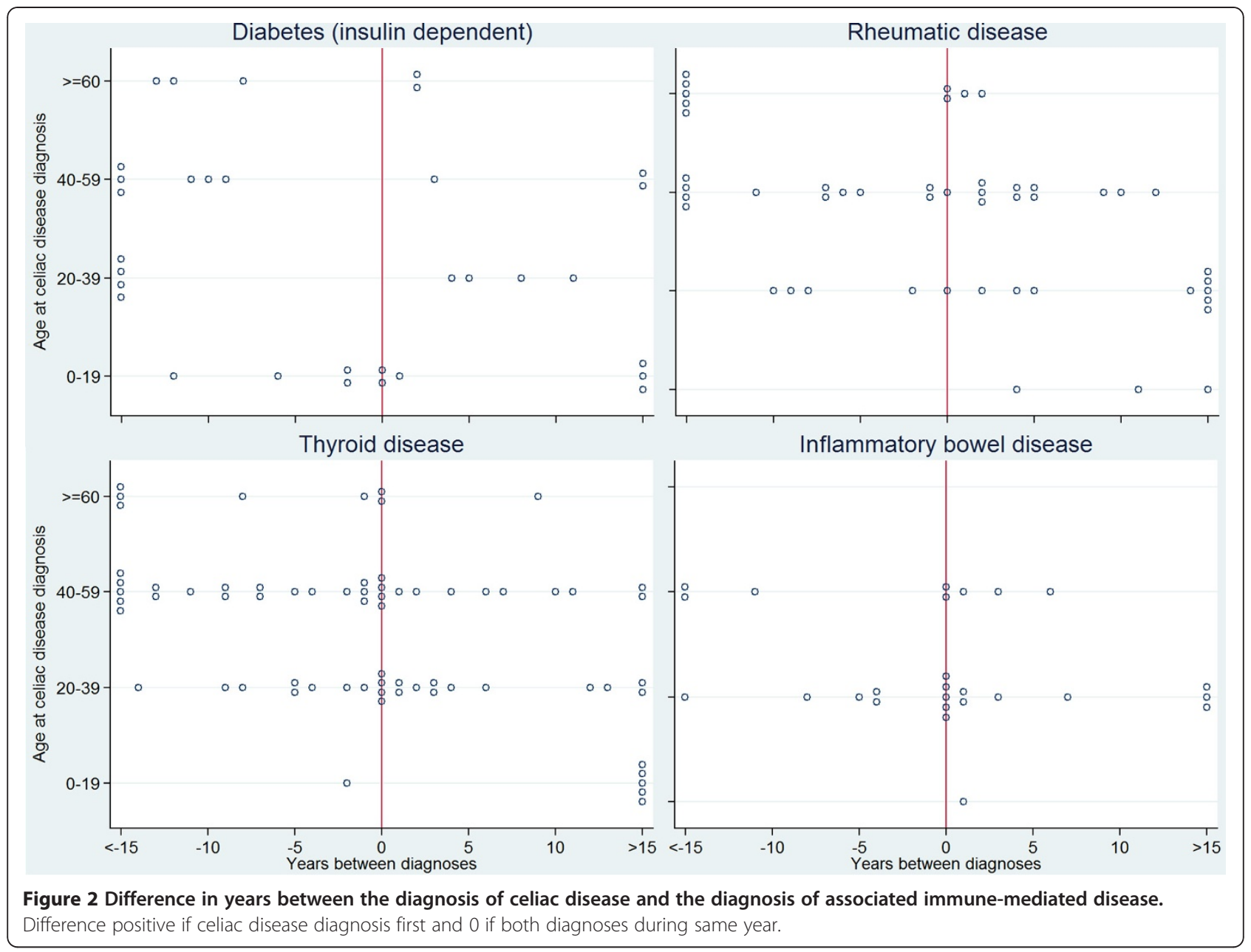

Previously, similar comparisons were done for a more limited number of symptoms by Murray and colleagues in the United States, showing a similar positive pattern for investigated symptoms after initiated treatment for CD [26]. Also Ukkola with colleagues showed an improvement in symptoms after initiated treatment with a gluten-free diet for Finnish CD patients [27]. Little is known about the added costs of $C D$ for individuals and society. Although many participants had their $\mathrm{CD}$ for a long time, and therefore were considerably older today, their health consumption was significantly lower today than prior to the $\mathrm{CD}$ diagnosis, indicating a decreased need for health care after initiated treatment with a gluten-free diet.

There is a well-known association between $\mathrm{CD}$ and other immune-mediated diseases [1]. A protective effect of a gluten-free diet was proposed more than a decade ago $[16,28]$, but later studies have shown conflicting results [15,18]. In our study $25 \%$ of the individuals reported associated immune-mediated diseases. The prevalences of autoimmune thyroid disease and diabetes mellitus type 1 were similar to figures previously reported in a Swedish CD population study based on patient chart reviews [25]. Our results could not verify or reject a risk reduction effect of a gluten-free diet on the development of any of the associated immune-mediated diseases that were studied. Further studies are needed to investigate this relationship.

In a previous publication based on the same study population and questionnaire, we reported that there is a long delay until CD diagnosis and that $\mathrm{CD}$ patients experience a poor health-related quality of life that is significantly improved after initiation of a gluten-free diet [5]. Considering this and the results of the present study, there is a strong implication that greater effort must be made to diagnose $\mathrm{CD}$ earlier to decrease the burden of both poorer health-related quality of life and CD-related symptoms. This would also result in economic savings for society in terms of a reduction in health care consumption and missed working days.

Recent studies have indicated that the extent of symptoms that patients detected through a population-based CD screening might have may be similar to that of nonCD persons $[29,30]$. The screening-detected cases in our 
study were mainly from risk groups. They reported the same positive effect of symptom relief after diagnosis and initiated treatment with a gluten-free diet as the $C D$ patients who had their primary investigation due to symptoms.

\section{Conclusion}

In conclusion, $\mathrm{CD}$ patients profit from being diagnosed and treated with a gluten-free diet, since this reduces both symptoms and health care consumption. An earlier celiac disease diagnosis is therefore of great importance. The possible protective role of a gluten-free diet regarding the development of other immune-mediated diseases remains to be demonstrated.

\section{Competing interests}

The authors declare that they have no competing interests.

\section{Authors' contributions}

Study design by FN, Al, and LL. FN coordinated data acquisition. FN performed the analyses and the interpretation in collaboration with $\mathrm{Al}, \mathrm{LL}$, and OS. FN drafted the paper and all co-authors contributed actively. All authors read and approved the final manuscript.

\section{Acknowledgements \\ We thank all who responded to the questionnaire, as well as the Swedish Society for Coeliacs for their assistance in improving the questionnaire and their crucial administrative help. The study was funded by the Swedish Research Council, the Swedish Research Council for Environment, Agricultural Sciences and Spatial Planning, and the Swedish Council for Working Life and Social Research. The study was undertaken at the Umeå Centre for Global Health Research at Umeå University.}

\section{Author details}

'Department of Public Health and Clinical Medicine, Epidemiology and Global Health, Umeå University, Umeå, Sweden. ${ }^{2}$ Department of Clinical Sciences, Pediatrics, Umeå University, Umeå, Sweden.

Received: 16 December 2011 Accepted: 30 August 2012

Published: 17 September 2012

\section{References}

1. Di Sabatino A, Corazza GR: Coeliac disease. Lancet 2009, 373:1480-1493.

2. Roma E, Panayiotou J, Karantana H, Constantinidou C, Siakavellas SI, Krini M, Syriopoulou VP, Bamias G: Changing pattern in the clinical presentation of pediatric celiac disease: a 30-year study. Digestion 2009, 80:185-191.

3. Cranney A, Zarkadas M, Graham ID, Butzner JD, Rashid M, Warren R, Molloy M, Case S, Burrows V, Switzer C: The Canadian celiac health survey. Dig Dis Sci 2007, 52:1087-1095.

4. Gray AM, Papanicolas IN: Impact of symptoms on quality of life before and after diagnosis of coeliac disease: results from a UK population survey. BMC Health Serv Res 2010, 10:105.

5. Norström F, Lindholm L, Sandström O, Nordyke K, Ivarsson A: Delay to celiac disease diagnosis and its implications for health-related quality of life. BMC Gastroenterol 2011, 11:118

6. Lee AR, Ng DL, Zivin J, Green PHR: Economic burden of a gluten-free diet. J Hum Nutr Diet 2007, 20:423-430

7. Roos S, Wilhelmsson S, Hallert C: Swedish women with coeliac disease in remission use more health care services than other women: a controlled study. Scand I Gastroenterol 2011, 46:13-19.

8. Long KH, Rubio-Tapia A, Wagie AE, Melton LJ, Lahr BD, Van Dyke CT, Murray JA: The economics of coeliac disease: a population-based study. Aliment Pharmacol Ther 2010, 32:261-269.

9. Green PH, Neugut Al, Naiyer AJ, Edwards ZC, Gabinelle S, Chinburapa V: Economic benefits of increased diagnosis of celiac disease in a national managed care population in the United States. J Insur Med 2008, 40:218-228.

10. Collin $P$, Kaukinen $K$, Välimäki $M$, Salmi J: Endocrinological disorders and celiac disease. Endocr Rev 2002, 23:464-483.

11. Ludvigsson JF, Ludvigsson J, Ekbom A, Montgomery SM: Celiac disease and risk of subsequent type 1 diabetes - a general population cohort study of children and adolescents. Diabetes Care 2006, 29:2483-2488

12. Sattar N, Lazare F, Kacer M, Aguayo-Figueroa L, Desikan V, Garcia M, Lane A, Chawla A, Wilson T: Celiac disease in children, adolescents, and young adults with autoimmune thyroid disease. J Pediatr 2011, $158: 272-275$.

13. Leeds JS, Hoeroldt BS, Sidhu R, Hopper AD, Robinson K, Toulson B, Dixon L, Lobo AJ, MCAlindon ME, Hurlstone DP, Sanders DS: Is there an association between coeliac disease and inflammatory bowel diseases? A study of relative prevalence in comparison with population controls. Scand J Gastroenterol 2007, 42:1214-1220.

14. Elfström P, Montgomery SM, Kämpe O, Ekbom A, Ludvigsson JF: Risk of thyroid disease in individuals with celiac disease. $J$ Clin Endocrinol Metab 2008, 93:3915-3921.

15. Meloni A, Mandas C, Jores RD, Congia M: Prevalence of autoimmune thyroiditis in children with celiac disease and effect of gluten withdrawal. J Pediatr 2009, 155:51-55.

16. Ventura A, Magazzu G, Greco L: Duration of exposure to gluten and risk for autoimmune disorders in patients with celiac disease. SIGEP study group for autoimmune disorders in celiac disease. Gastroenterology 1999 117:297-303.

17. Cosnes J, Cellier C, Viola S, Colombel JF, Michaud L, Sarles J, Hugot JP, Ginies JL, Dabadie A, Mouterde O, et al: Incidence of autoimmune diseases in celiac disease: protective effect of the gluten-free diet. Clin Gastroenterol Hepatol 2008, 6:753-758.

18. Sategna Guidetti C, Solerio E, Scaglione N, Aimo G, Mengozzi G: Duration of gluten exposure in adult coeliac disease does not correlate with the risk for autoimmune disorders. Gut 2001, 49:502-505.

19. Viljamaa M, Kaukinen K, Huhtala H, Kyrönpalo S, Rasmussen M, Collin P: Coeliac disease, autoimmune diseases and gluten exposure. Scand Gastroenterol 2005, 40:437-443.

20. Metso S, Hyytiä-IImonen H, Kaukinen K, Huhtala H, Jaatinen P, Salmi J, Taurio J, Collin P: Gluten-free diet and autoimmune thyroiditis in patients with celiac disease. A prospective controlled study. Scand J Gastroenterol 2011, 47:43-48.

21. To you, a member of the Swedish Society for Coeliacs: Your experience is important! http://www.biomedcentral.com/imedia/5468125862231012/ supp1.pdf.

22. Hopper AD, Hadjivassiliou M, Hurlstone DP, Lobo AJ, Mcalindon ME, Egner W, Wild G, Sanders DS: What is the role of serologic testing in celiac disease? A prospective, biopsy-confirmed study with economic analysis. Clin Gastroenterol Hepatol 2008, 6:314-320.

23. Bardella MT, Fredella C, Saladino V, Trovato C, Cesana BM, Quatrini M, Prampolini L: Gluten intolerance: gender- and age-related differences in symptoms. Scand J Gastroenterol 2005, 40:15-19.

24. Dinler G, Atalay E, Kalayci AG: Celiac disease in 87 children with typical and atypical symptoms in Black Sea region of Turkey. World J Pediatr 2009, 5:282-286

25. Ludvigsson JF, Brandt L, Montgomery SM: Symptoms and signs in individuals with serology positive for celiac disease but normal mucosa. BMC Gastroenterol 2009, 9:57.

26. Murray JA, Watson T, Clearman B, Mitros F: Effect of a gluten-free diet on gastrointestinal symptoms in celiac disease. Am J Clin Nutr 2004, 79:669-673.

27. Ukkola A, Mäki M, Kurppa K, Collin P, Huhtala H, Kekkonen L, Kaukinen K: Diet improves perception of health and well-being in symptomatic, but not asymptomatic, patients with celiac disease. Clin Gastroenterol Hepatol 2011, 9:118-123.

28. Ventura A, Neri E, Ughi C, Leopaldi A, Citta A, Not T: Gluten-dependent diabetes-related and thyroid-related autoantibodies in patients with celiac disease. J Pediatr 2000, 137:263-265.

29. Katz KD, Rashtak S, Lahr BD, Melton LJ, Krause PK, Maggi K, Talley NJ, Murray JA: Screening for celiac disease in a North American population: sequential serology and gastrointestinal symptoms. Am J Gastroenterol 2011, 106:1333-1339. 
30. Godfrey JD, Brantner TL, Brinjikji W, Christensen KN, Brogan DL, Van Dyke $\mathrm{CT}$, Lahr BD, Larson JJ, Rubio-Tapia A, Melton LJ, et al: Morbidity and mortality among older individuals with undiagnosed celiac disease. Gastroenterology 2010, 139:763-769.

doi:10.1186/1471-230X-12-125

Cite this article as: Norström et al: A gluten-free diet effectively reduces symptoms and health care consumption in a Swedish celiac disease population. BMC Gastroenterology 2012 12:125.

\section{Submit your next manuscript to BioMed Central} and take full advantage of:

- Convenient online submission

- Thorough peer review

- No space constraints or color figure charges

- Immediate publication on acceptance

- Inclusion in PubMed, CAS, Scopus and Google Scholar

- Research which is freely available for redistribution 